\title{
Ibm SURVEY PEMETAAN BADAN JALAN SEKTOR SELATAN UNIVERSITAS LANCANG KUNING PEKANBARU
}

\author{
Fadrizal lubis*1, Winayati $^{2}$, Virgo Trisep Haris ${ }^{3}$ \\ Program Studi Teknik Sipil Fakultas Teknik Universitas Lancang Kuning \\ Jl.Yos Sudarso Km.8 Rumbai-Pekanbaru \\ e-mail: fadrizal@unilak.ac.id
}

\begin{abstract}
In carrying out a development, need to be based on clear direction and objectives, so that the results achieved can be more optimal. The number of students, staff and lecturers each year shows improvement, it certainly requires supporting facilities both facilities and infrastructure. Thus the existence of University of Lancang Kuning in the middle of society really can be felt. The most important means in this activity is the availability of road infrastructure or access in and out of the southern sector, to provide the roads with a measurement of the location, shape, elevation and span of the road to be planned.

Methods performed in the activities of community service, among others, starting from the preparation of administration, preliminary survey implementation, measuring data directly in the field, resulting in a topographic image that can be utilized by the University of Lancang Kuning in planning the next road trase in the south.

The results obtained from this activity for partners is to obtain information such as measurement data, line topography and the volume of the pile of road bodies located at Sta $0+$ 075 to Sta $0+525$ and the length of the measured road is 707 meters wide 4.5 meters, from this data if the partners are willing to plan or develop the road to a width of 7 meters of road, 1 meter shoulder and drainage between 0.6-0.8 meters can be done, in addition to the participants of this activity both lecturers and students can apply special knowledge in the field of measurement or survey mapping.
\end{abstract}

Keywords: Road Traffic, Contour Line and Heap Volume.

\begin{abstract}
Abstrak
Dalam melaksanakan suatu pembangunan, perlu didasarkan pada arah dan tujuan yang jelas, sehingga hasil yang dicapai dapat lebih optimal. Jumlah mahasiswa, karyawan dan dosen setiap tahunnya menunjukkan peningkatan, hal ini tentu membutuhkan fasilitas pendukung baik sarana maupun prasarananya. Dengan demikian keberadaan Universitas Lancang Kuning ditengah-tengah masyarakat benar-benar dapat dirasakan. Sarana yang terpenting dalam kegiatan ini adalah tersedianya infrastruktur jalan atau akses keluar-masuk pada sektor selatan, untuk menyediakan jalan tersebut perlu dilakukan pengukuran terhadap letak, bentuk, elevasi dan bentang jalan yang akan direncanakan.

Metode yang dilakukan dalam kegiatan pengabdian kepada masyarakat ini antara lain dimulai dari persiapan administrasi, survey awal pelaksanaan, pengambilan data ukur secara langsung dilapangan, sehingga menghasilkan produk berupa gambar topografi yang dapat dimanfaatakan oleh pihak Universitas Lancang Kuning dalam melakukan perencanaan trase jalan disektor selatan berikutnya.

Hasil yang diperoleh dari kegiatan ini bagi mitra kerja adalah mendapatkan informasi seperti data ukur, garis kountur (topografi) serta besaran volume timbunan badan jalan yang berada pada Sta 0+075 sampai dengan Sta 0+525 dan panjang jalan yang diukur adalah 707 meter dengan lebar 4,5 meter, dari data ini jika mitra kerja mau merencanakan atau mengembangkan jalan tersebut menjadi lebar badan jalan 7 meter, bahu jalan 1 meter dan drainase antara 0,6-0,8 meter sudah dapat dilakukan, disamping itu bagi peserta pelaksana kegiatan ini baik dosen maupun mahasiswa dapat menerapkan ilmu khsususnya pada bidang pengukuran atau survey pemetaan.
\end{abstract}

Kata Kunci : Trase Jalan, Garis kountur dan Volume timbunan. 


\section{PENDAHULUAN}

Dalam pelaksanaan pembangunan kota atau suatu Wilayah, perlu didasarkan kepada arah dan tujuan yang jelas sehingga dapat dicapai hasil yang optimal, Oleh karenanya sebagai urgensi yang sangat normatif dalam suatu pembangunan diperlukan perencanaan tata ruang yang memuat konsep arah pengembangannya melalui identifikasi dan potensi daerah atau wilayah yang menjadi unsur utama dalam pengembangannya dan salah satunya adalah keberadaan Universitas Lancang Kuning ditengah masyarakat.

Kebutuhan akan ketersediaan fasilitas pendukung sebuah perguruan tinggi tentu sangat komplek contohnya tersedianya gedung rektorat, gedung perkuliahan, perpustaaan, lapangan olah raga, gedung labolatorium, masjid atau musholla, aksesibiltas jalan keluar-masuk, penerangan, restoran, dan lain sebagainya tentu semua ketersediaan itu tidak dapat dihasilkan secara langsung dan membutuhkan tahapan pelaksanaan pembangunannya.

Hasil evaluasi yang dilakukan terhadap mitra adalah sampai dengan tahun 2017 jumlah mahasiswa yang aktif kuliah di Universitas Lancang Kuning Pekanbaru lebih kurang berjumlah 13500 mahasiswa ditambah dengan dosen dan karyawannya(sumber:BAAK-Unilak,2017), dan tentu hal ini membutuhkan ketersediaan fasilitas pendukung dan tersedianya pelayanan sarana dan prasarana yang memadai dan kegiatan ini juga dapat memberikan ilmu dilapangan bagi peserta pengabdian baik dosen maupun mahasiswa .

\section{METODE}

\subsection{Persiapan Administrasi}

Persiapan administrasi ini dilakukan guna memastikan surat-menyurat tentang pelaksanaan sudah tersedia dan tidak lagi bermasalah antara lain :
a. Surat tugas personil pelaksana.
b. Surat izin survey.
c. Surat persetujuan mitra kerja.

\subsection{Persiapan teknik pelaksana dilapangan}

Persiapan teknik pelaksana dilapangan yang perlu disediakan antara lain :

a. penyediaan peta kerja

b. penyediaan deskripsi titik dan ketinggian yang telah ada di lokasi pemetaan

c. Koordinasi dilapngan berupa penerapan K-3L dan Komunikasi

d. pemeriksaan kondisi fisik serta kebenaran koordinat dan ketinggian titik ikat yang akan digunakan

e. penetapan titik ikat dan ketinggian yang akan digunakan

f. penentuan letak base camp

g. perencanaan jalur pengukuran

h. perencanaan letak pemasangan patok tetap

i. penyediaan patok tetap utama dan patok tetap bantu

j. penyediaan patok sementara

k. perencanaan sistem pemberian nomor patok sementara dan nomor patok tetap

1. penyediaan alat ukur yang sesuai dengan ketelitian yang telah ditetapkan

m. kalibrasi alat ukur

n. penyediaaan alat hitung

o. penyediaan formulir data ukur dan formulir data hitungan

p. penyediaan tabel deklinasi untuk tahun pelaksanaan pengamatan matahari

\subsection{Persiapan Managerial}

Persiapan manajerial yang harus dilakukan dalam pelaksanaan kegiatan pengukuran ini antara lain berupa :

a. pembuatan jadwal pelaksanaan pekerjaan,

b. pembuatan struktur organisasi pelaksanaan pekerjaan,

c. pemberian pengarahan dan pemahaman pada personil pelaksana rencana tentang kerja. 
d. Rapat-rapat persiapan dan melakukan koordinasi dengan team pelaksana

e. penyusunan laporan pendahuluan dan laporan akhir.

f. hal-hal lain yang diperlukan.

\subsection{Pengolahan data}

Dalam perhitungan data, team pengabdian mengkombinasikan data koordinat GPS dengan data Thedolit sehingga menjadi satu sistem koordinat dalam rangkaian poligon terbuka. Adapun tahap perhitungannya antara lain :

a. Menghitung nilai keseksamaan poligon.

Tahapannya adalah menggunakan titik acuan koordinat GPS, menghitung azimut dan jarak antara titik poligon, salah penutup sudut, salah penutup absis, salah penutup ordinat dan salah penutup jarak.

b. Menghitung koordinat titik poligon.

Berdasarkan nilai keseksamaan poligon dapat dibandingkan dengan keseksamaan yang diizinkan, jika hasilnya memenuhi syarat maka dihitung selisih koordinat masing-masing titik poligon dan dijumlahkan dengan titik acuan koordinat GPS, maka dapat koordinat titik poligon.

c. Menghitung koordinat situasi.

Berdasarkan data ukur topografi dapat dihitung sudut jurusan, jarak, selisih X, selisih $\mathrm{Y}$ dan dijumlahkan dengan koordinat titik poligon.

d. Gambar peta topografi.

Data yang digunakan adalah nilai koordinat masing-masing titik dengan mengunakan program Auto Cad Land Development Destop.

\subsection{Data galian dan timbunan}

Untuk menghitung galian dan timbunan tanah berdasarkan irisan penampang maupun melintang jalan. Pengolahan data dilakukan dengan cara sebagai berikut :

a. Tempatkan titik mana yang akan digunakan untuk irisan penampang memanjang maupun melintang.

b. Gambarkan masing-masing irisan penampang memanjang maupun melintan yang bersangkutan dan perlihatkan perbedaan tinggi muka tanah asli dengan tinggi permukaan perkerasan yang direncanakan.

c. Dengan menggunakan Planimetri atau milimeter kolom hitung masing -masing luas penampang galian dan timbunan dengan cermat

d. Setelah luas masing -masing irisan penampang memanjang maupun melintang diperoleh, selanjutnya hitung volume timbunan masing-masing irisan.

e. Hitung total jumlah volume galian dan timbunan tanah tersebut. Untuk mempermudah dalam perhitungan digunakan format atau table.

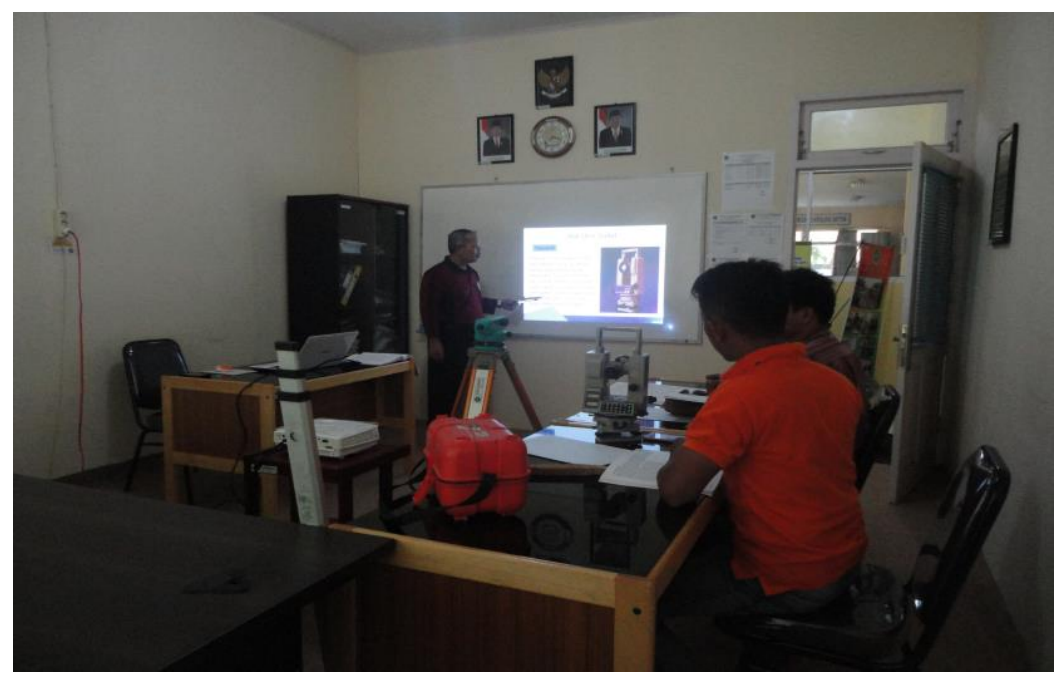

Gambar 1. Sosialisasi bagi pelaksana kegiatan 


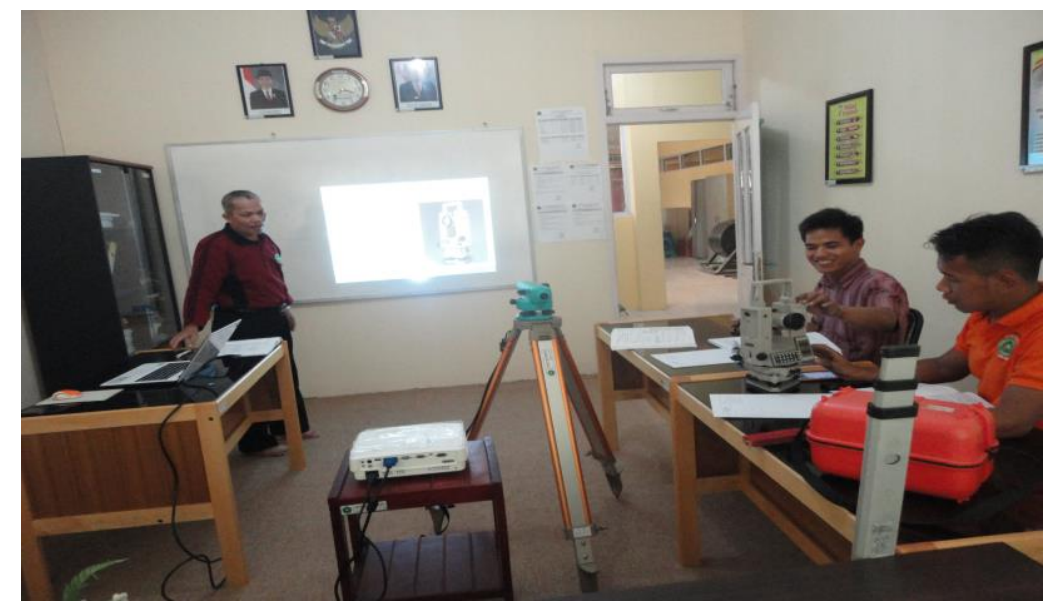

Gambar 2. Penjelasan penggunaan alat survey

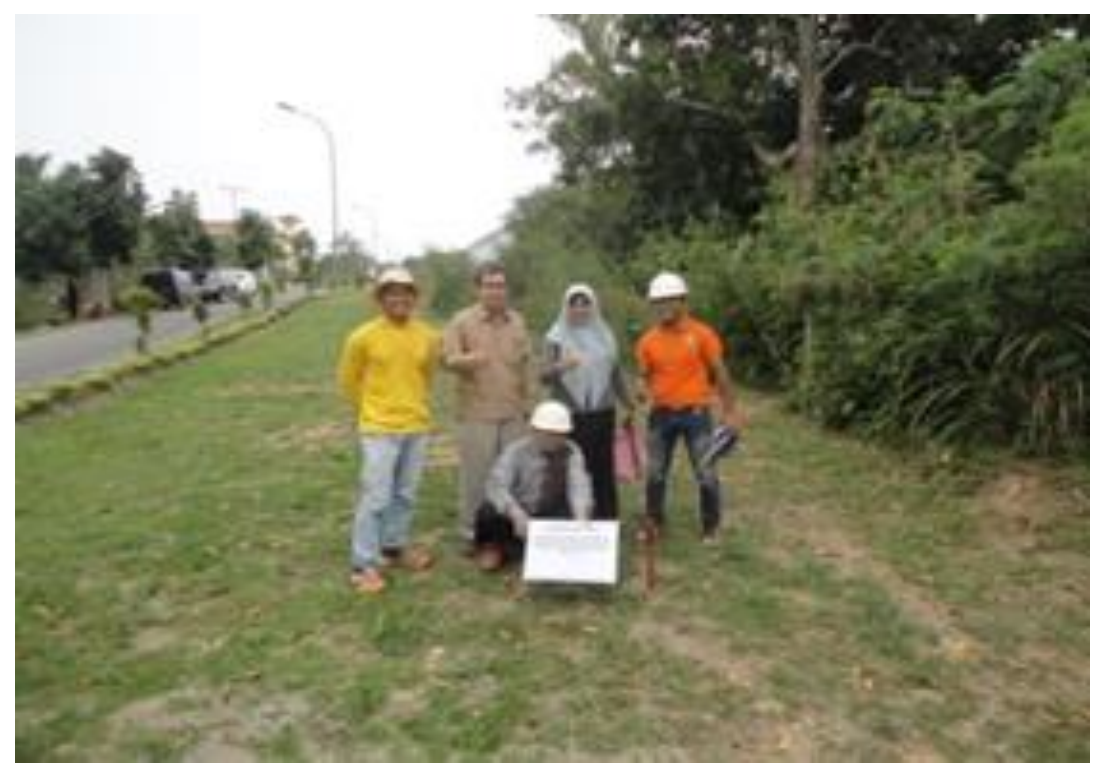

Gambar 3. Kegiatan survey awal dilapangan

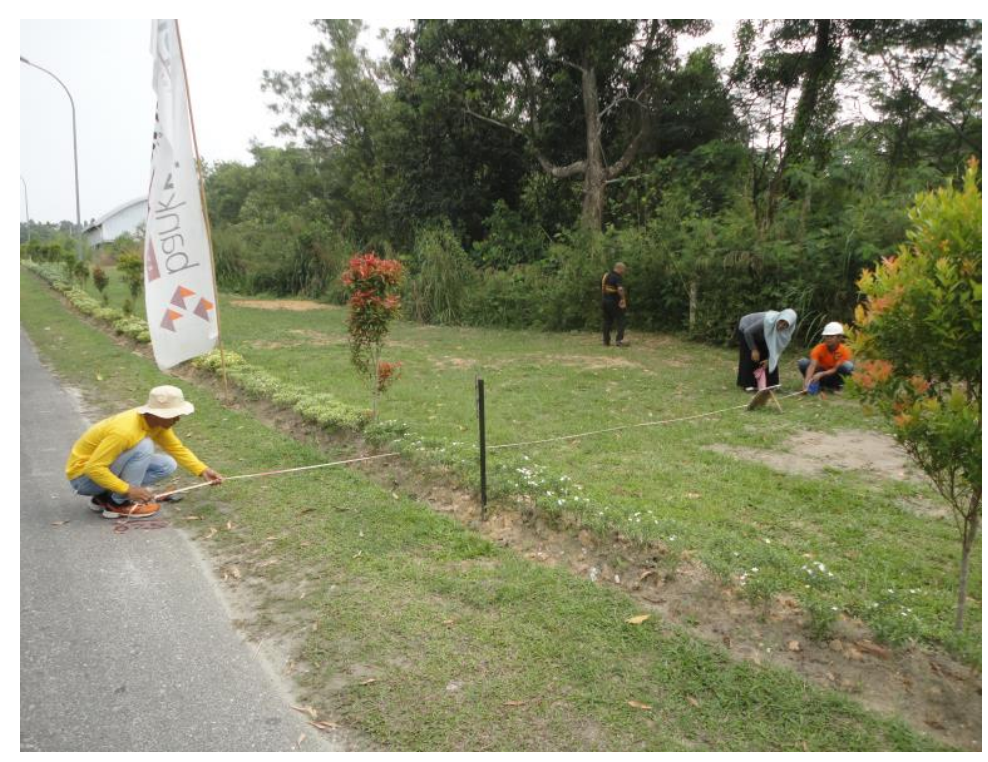

Gambar 4. Kegiatan pengukuran awal dilapangan 


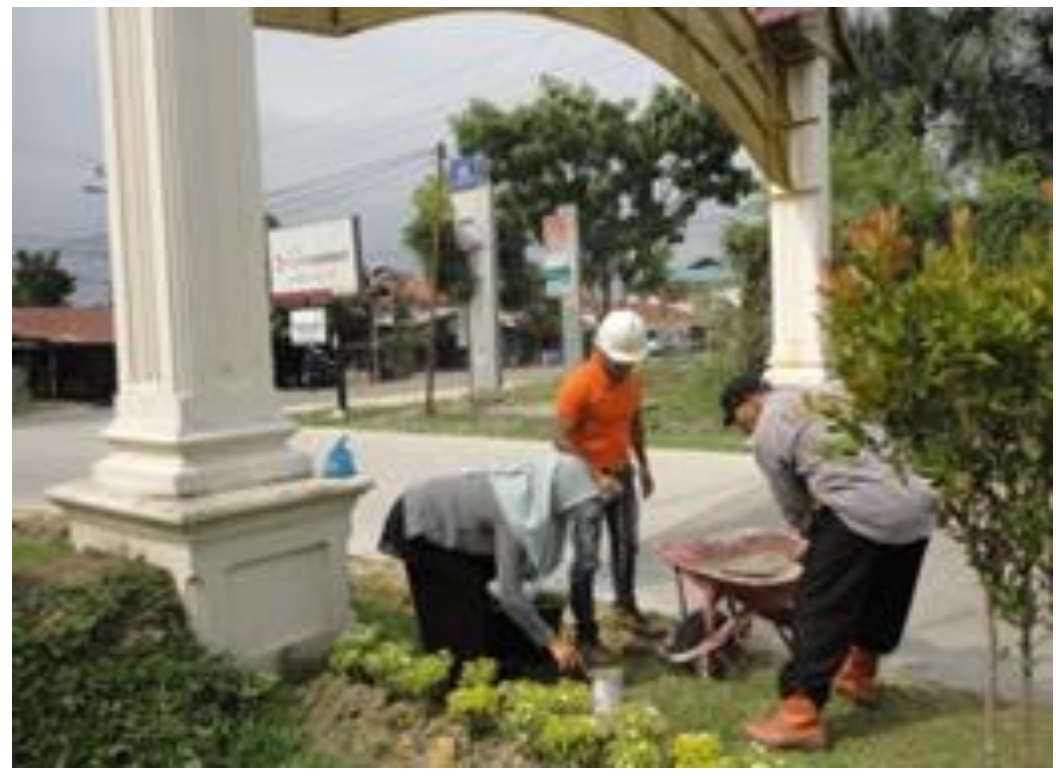

Gambar 5. Kegiatan pemasangan titik Benchmark pengukuran

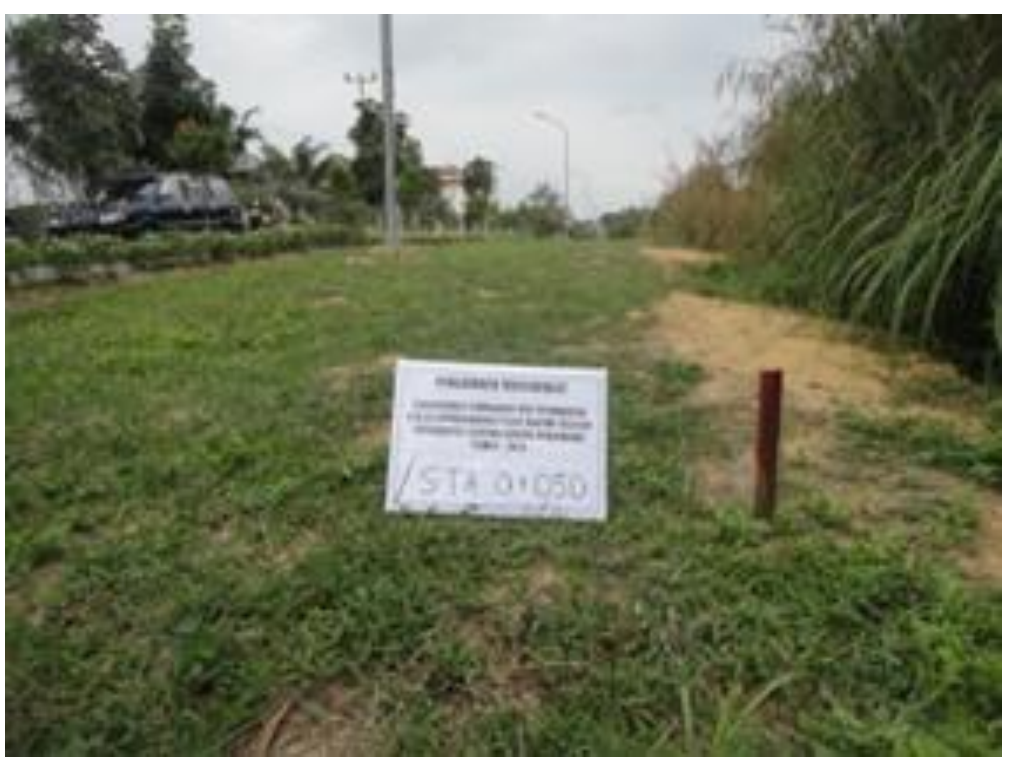

Gambar 6. Pemasangan patok pengukuran dilapangan

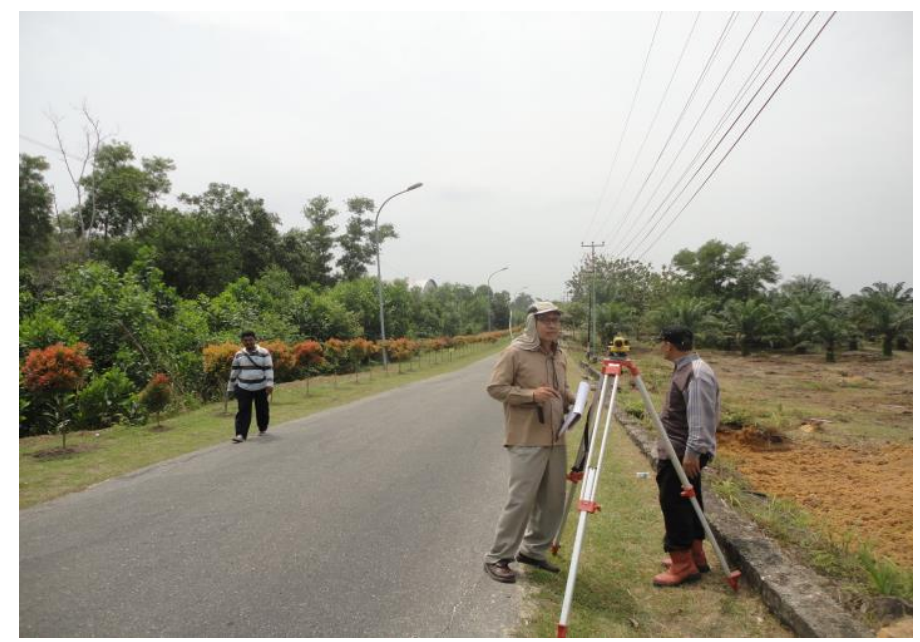

Gambar 7. Kegiatan pengambilan data dilapangan 


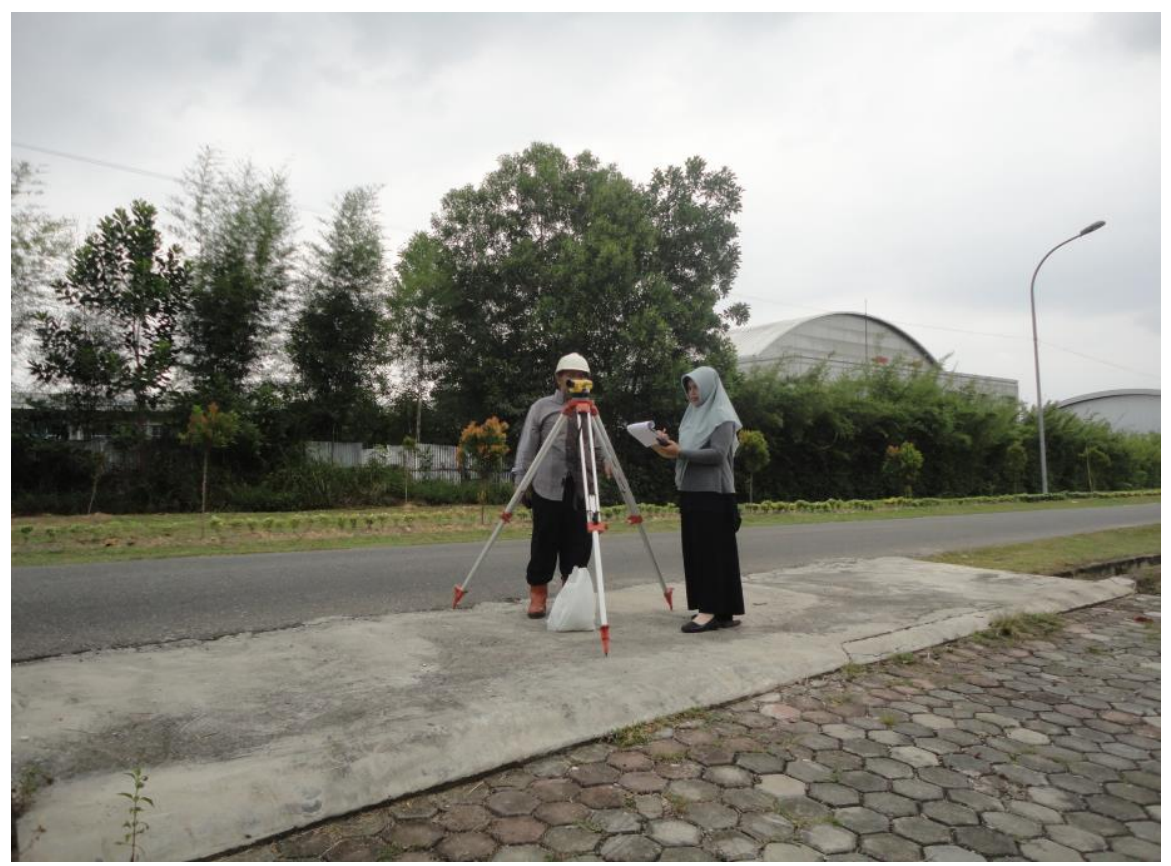

Gambar 8. Kegiatan pengambilan data dilapangan

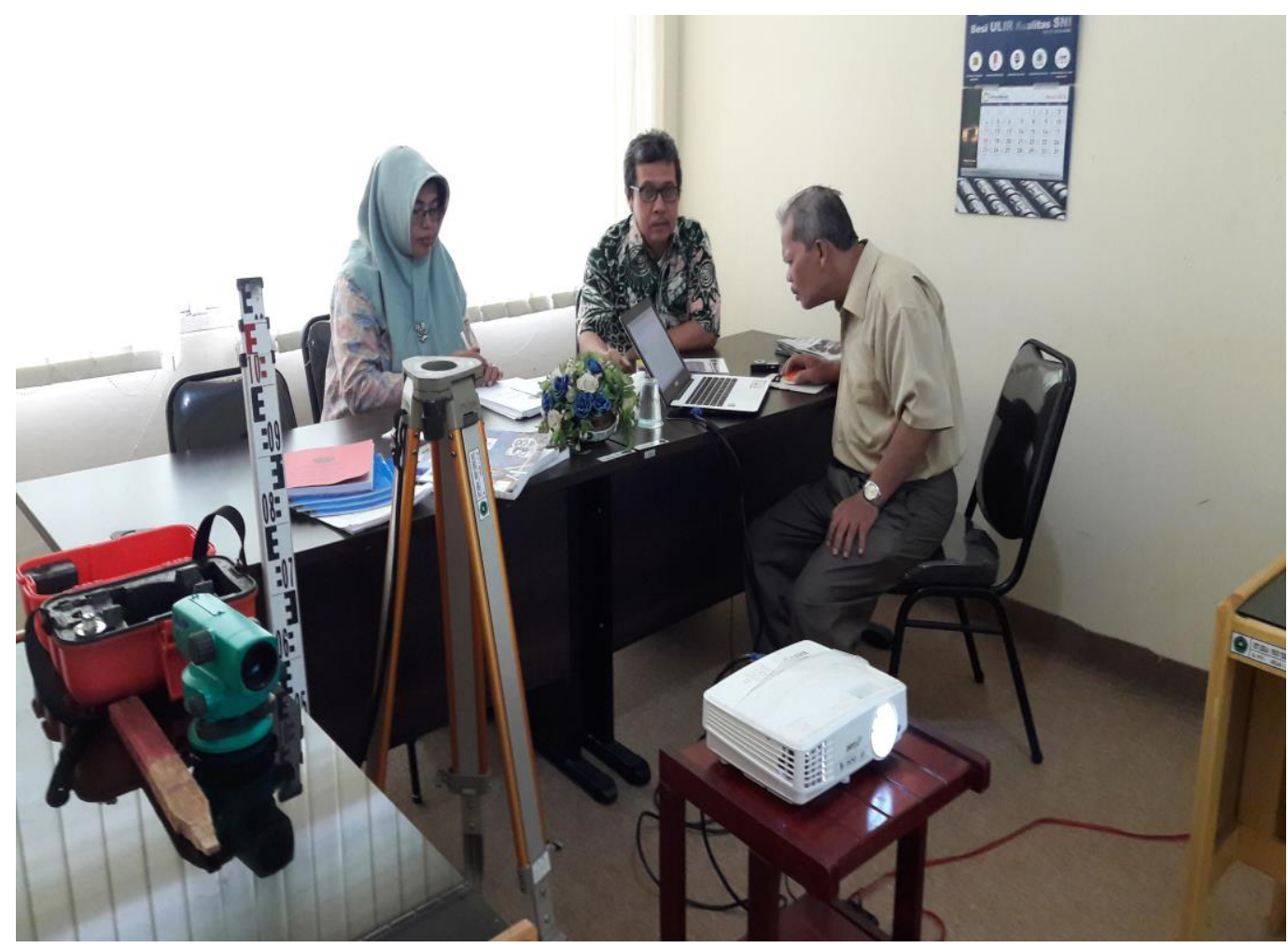

Gambar 8. Kegiatan koordinasi team dalam penyusunan laporan 


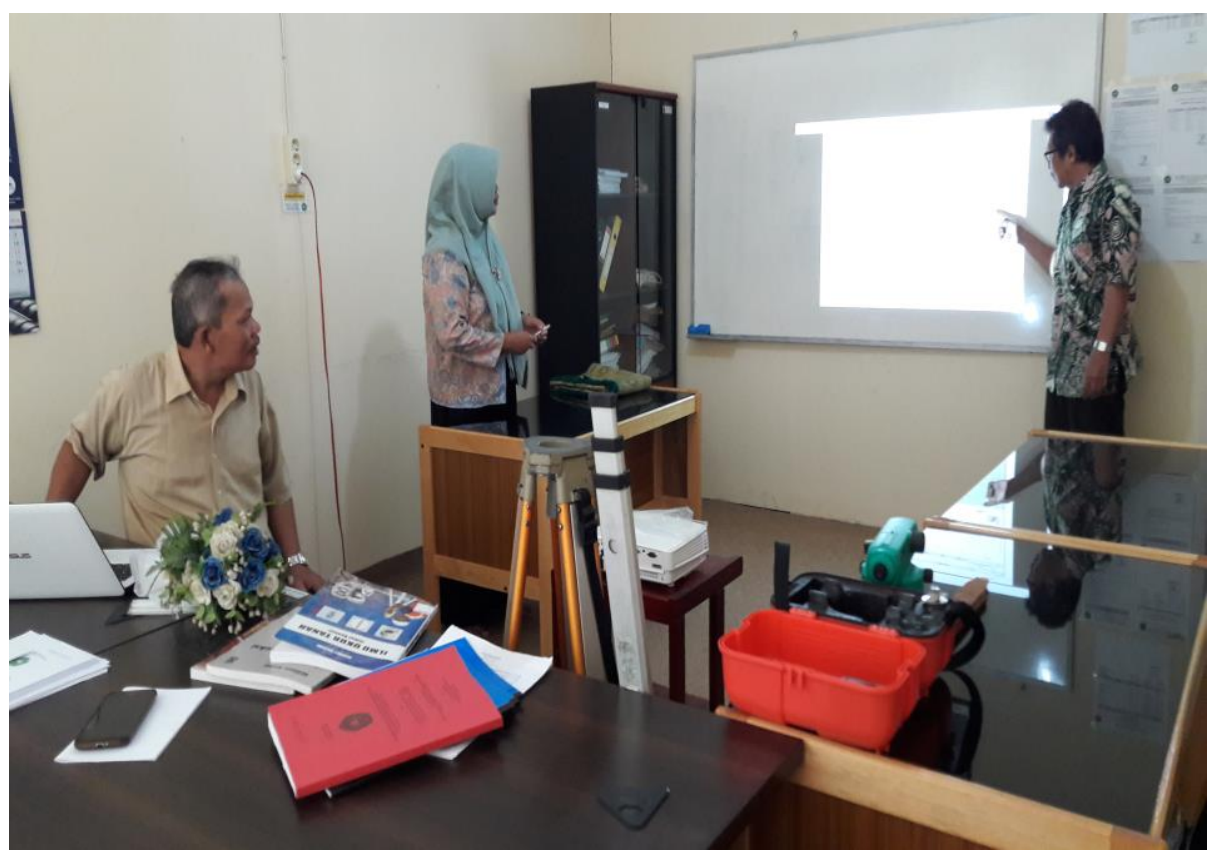

Gambar 9. Kegiatan penjelasan cara pengambaran hasil survey

\section{HASIL DAN PEMBAHASAN}

Dalam melaksanakan kegiatan pengukuran dilapangan perlu juga perhatikan atau diterapkan sistem keselamatan dan kesehatan kerja dan lingkungan (K-3L) yang berfungsi untuk menghindari jika terjadi kecelakaan pada personil maupun peralatan yang digunakan, termasuk juga melakukan dan menerapkan komunikasi ditempat kerja dengan sehingga informasi yang diperlukan dapat dipahami oleh semua personil pengukuran.

Kegiatan pengukuran ini berlokasi diJalan Sektor Selatan Kampus Universitas Lancang Kuning yang dilaksanakan pada tanggal 4 s.d 11 Februari 2018, maksud dilaksanakannya kegiatan ini adalah untuk dapat mengumpulkan data pengukuran secara langsung dilapangan, panjang jalan yang diukur adalah 707 meter dengan lebar jalan 4,5 meter dari kegiatan ini kita akan mendapatkan garis kountur (topografi) pada jalan tersebut, serta mendapatkan besaran volume penimbunan tanah pada badan jalan tersebut yang berada pada Sta 0+075 sampai dengan Sta 0+525, Hasil dan luaran yang dicapai pada kegiatan ini dapat dilihat pada gambar berikut .

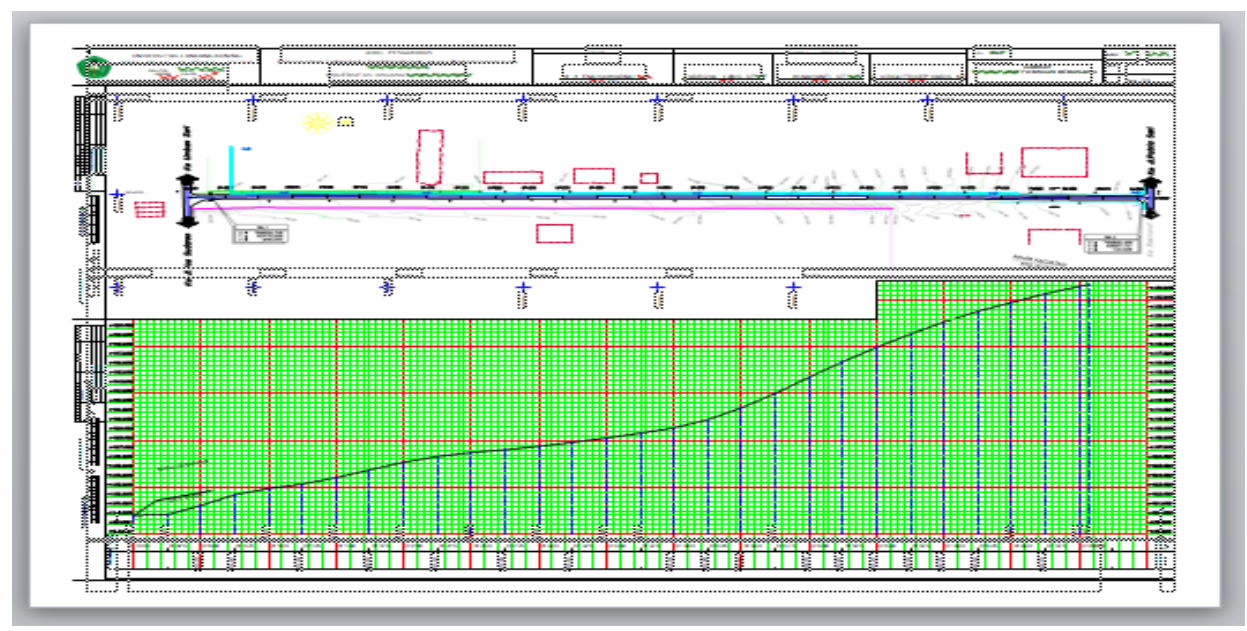


Gambar 10. Garis kountur/topografi jalan

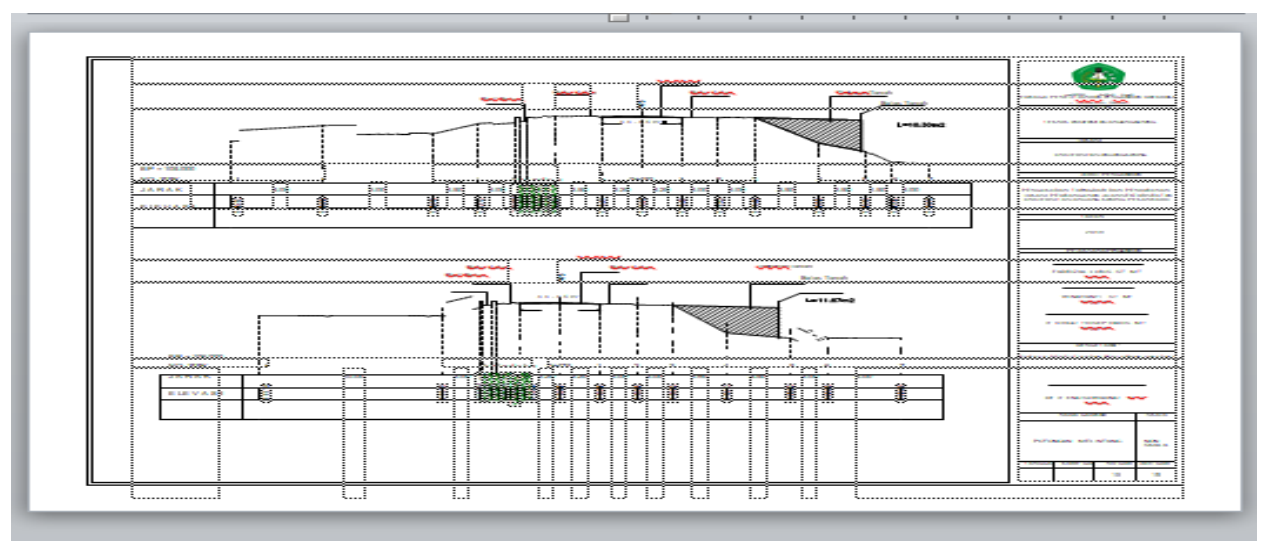

Gambar 11. Contoh Potongan melintang jalan

\section{KESIMPULAN}

Pelaksanaan pengabdian kepada masyarakat ini dengan judul Pengukuran Topografi dan Penimbunan Lokasi Pembangunan Jalan Sektor Selatan Universitas Lancang Kuning Pekanbaru, hal ini merupakan salah satu kegiatan yang dilaksanakan oleh Dosen-dosen di Program Studi Teknik Sipil dan mahasiswa dan salah satu bentuk pelaksanaan Tri Dharma Perguruan Tinggi. Adapun kesimpulan serta saran yang dapat ditarik dari kegiatan ini antara lain :

1. Pelaksanaan pengukuran dilapangan sudah dilaksanakan pada tanggal 4-11 Februari 2018 oleh team pengabdian kepada masyarakat di Prodi Teknik Sipil.

2. Panjang Jalan yang dilakukan pengukurannya adalah lebih kurang sepanjang 707 meter dengan lebar jalan 4,5 meter, dari data ini bagi mitra kerja akan dapat mengembangkan jalan tersebut menjadi 2 jalur dengan lebar 7 meter, bahu jalan 1 meter dan lebar drainasenyaa antara 0,6-0,8 meter.

3. Metode yang dilaksanakan dilapangan adalah antara lain melakukan persiapan dilapangan baik terhadap personil maupun peralatan yang digunakan sehingga tidak terjadi kesalahan, persiapan administrasi, persiapan managenial dan lain sebagainya.

4. Penerapan Keselamatan Kesehatan Kerja dan Lingkungan (K-3L) sangat penting demi keamanan dari personil pengukuran maupun terhadap peralatan yang digunakan, serta penerapan komunikasi ditempat kerja sehingga informasi akan tersampaikan dengan baik

5. Bagi mitra kerja hasil yang didapatkan adalah gambar kountur (topografi) jalan tersebut serta berasan volume tanah yang diperlukan untuk melakukan menimbunan di badan jalan yang akan direncanakan berikutnya, terutama pada sta 0+075 - 0+525.

6. Bagi peserta kegiatan Pengabdian Kepada Masyarakat baik dosen maupun mahasiswa dapat menerapkan ilmunya dilapangan terutama pada kegiatan pengukuran atau melakukan survey pemetaan.

\section{SARAN}

1. Melaksanakan suatu kegiatan pekerjaan dilapangan diperlukan koordinasi yang jelas antar pekerja maupun dengan atasannya sehingga melaksanakan komunikasi sangat diperlukan dengan demikian pekerjaan yang sedang dilakukan dapat berjalan dengan baik. 
2. Agar terhindar dari hal-hal yang tidak diinginkan seperti kecelakaan kerja maka penerapan Keselamatan dan Kesehatan Kerja di Lapangan (K-3L) perlu dilakukan, dengan demikian produktifitas atau hasil pekerjaan dapat meningkat dan waktu pelaksanaan tidak terbuang begitu saja.

3. Akurasi data lapangan sangat penting dikerjakan sehingga hasil penggambaran yang dilakukan baik terhadap potongan memanjang maupun potongan melintang jalan serta garis kountur tanah benar-benar akan lebih sempurna.

4. Untuk dapat lebih bergunanya hasil pengukuran tersebut hendaknya pihak mitra kerja (Universitas Lancang Kuning) perlu melakukan langkah-langkah penerapan dilapangan dengan demikian hasil yang didapat tidak hilang begitu saja .

5. Dalam merencanakan trase jalan lebih lanjut data yang didapatkan bisa digunakan agar fasilitas sarana dan prasarana jalan (akses masuk) disektor selatan ini benar-benar termanfaatkan oleh pihak mitra kerja (Universitas Lancang Kuning).

6. Kegiatan dari hasil pengukuran bagi mitra kerja dapat dilanjutkan pada kegiatan perencanaan trase jalan maupun perencanaan drainasenya.

\section{UCAPAN TERIMA KASIH}

Dengan kerendahan hati dan rasa hormat penulis mengucapkan terima kasih kepada semua pihak khususnya pihak Universitas Lancang Kuning yang telah memberikan dukungan baik bersifat moril, financial terhadap penulisan ini, dengan harapan semoga tulisan ini dapat bermanfaat bagi semua.

\section{DAFTAR PUSTAKA}

[1] Adiwiyono.NS, 1995, Teknik membaca peta dan kompas, Angkasa, Bandung

[2] Abidin.HZ,dkk, 2002, Survey dengan GPS, Pradnya Paramita, Jakarta.

[3] Abidin.HZ, 2007, Penentuan posisi dengan GPS dan aplikasinya, Pradnya Paramita, Jakarta.

[4] Basuki,S, 2006, Ilmu Ukur Tanah, UGM Press, Yogyakarta

[5] Basuki,S, 2011, Ilmu Ukur Tanah (edisi revisi), UGM Press, Yogyakarta

[6] Hidayat.A, dkk, Januari 2014, Survey bathimetri untuk pengecekan perairan wilayah Kendal, Jurnal Geodesi Universitas Diponegoro.

[7] Irvine.W, 1995, Penyigian untuk konstruksi, ITB, Bandung.

[8] Lestari.ES, dkk, Januari 2014, Pembuatan program perataan parameter jarring polygon dengan menggunakan Visual Basic For Application (VBA) Microsoft Exel, Jurnal Geodesi Universitas Diponegoro.

[9] Muslim.FH, dkk, Januari 2017, Verifikasi letak segmen batas indikatif berdasarkan aspek teknik dan non-teknis (Studi kasus : Kecamatan Getasan, Kabupaten Semarang), Jurnal Geodesi Universitas Diponegoro

[10] Putri.KM, dkk, Januari 2017, Pembuatan peta wisata digital 3 domensi obyek wisata Brown Canyon secara interaktif dengan menggunakan wahana Unmanned Aerial Vehicle (UAV), Jurnal Geodesi Universitas Diponegoro.

[11] Rahmawan.LE,dkk, Oktober 2016, Survey pemantauan deformasi muka tanah kawasan pesisir menggunakan metode pengukuran GPS di Kabupaten Demak tahun 2016 (Studi Kasus : Pesisir Kecamatan Sayung, Demak), Jurnal Geodesi Universitas Diponegoro

[12] Subagio, 2003, Pengetahuan peta, ITB, Bandung

[13] Yusuf.MA, dkk, Oktober 2015, Pengamatan GPS untuk monitoring deformasi Bendungan Undip, Jurnal Geodesi Universitas Diponegoro 